\title{
Association analysis of nine candidate gene polymorphisms in Indian patients with type 2 diabetic retinopathy
}

\author{
Suganthalakshmi Balasubbu 1,2, Periasamy Sundaresan', Anand Rajendran ${ }^{3}$, Kim Ramasamy $^{3}$, \\ Gowthaman Govindarajan', Namperumalsamy Perumalsamy ${ }^{3}$, J Fielding Hejtmancik ${ }^{2,4^{*}}$
}

\begin{abstract}
Background: Diabetic retinopathy (DR) is classically defined as a microvasculopathy that primarily affects the small blood vessels of the inner retina as a complication of diabetes mellitus (DM).It is a multifactorial disease with a strong genetic component. The aim of this study is to investigate the association of a set of nine candidate genes with the development of diabetic retinopathy in a South Indian cohort who have type 2 diabetes mellitus (T2DM).

Methods: Seven candidate genes (RAGE, PEDF, AKR1B1, EPO, HTRA1, ICAM and HFE) were chosen based on reported association with DR in the literature. Two more, CFH and ARMS2, were chosen based on their roles in biological pathways previously implicated in DR. Fourteen single nucleotide polymorphisms (SNPs) and one dinucleotide repeat polymorphism, previously reported to show association with DR or other related diseases, were genotyped in 345 DR and 356 diabetic patients without retinopathy (DNR). The genes which showed positive association in this screening set were tested further in additional sets of 100 DR and 90 DNR additional patients from the Aravind Eye Hospital. Those which showed association in the secondary screen were subjected to a combined analysis with the 100 DR and 100 DNR subjects previously recruited and genotyped through the Sankara Nethralaya Hospital, India. Genotypes were evaluated using a combination of direct sequencing, TaqMan SNP genotyping, RFLP analysis, and SNaPshot PCR assays. Chi-square and Fisher exact tests were used to analyze the genotype and allele frequencies.

Results: Among the nine loci (15 polymorphisms) screened, SNP rs2070600 (G82S) in the RAGE gene, showed significant association with $D R$ (allelic $P=0.016$, dominant model $P=0.012$ ), compared to DNR. SNP rs2070600 further showed significant association with $D R$ in the confirmation cohort $(P=0.035$, dominant model $P=0.032$ ). Combining the two cohorts gave an allelic $P<0.003$ and dominant $P=0.0013)$. Combined analysis with the Sankara Nethralaya cohort gave an allelic $P=0.0003$ and dominant $P=0.00011$ with an $O R=0.49(0.34-0.70)$ for the minor allele. In HTRA1, rs11200638 (G>A), showed marginal significance with DR ( $=0.055)$ while rs 10490924 in LOC387715 gave a $P=0.07$. No statistical significance was observed for SNPs in the other 7 genes studied.
\end{abstract}

Conclusions: This study confirms significant association of one polymorphism only (rs2070600 in RAGE) with DR in an Indian population which had T2DM.

\section{Background}

Diabetic retinopathy (DR) is the second leading cause of blindness due to retinal degeneration, contributing to an overall $4.8 \%$ blindness across the globe [1]. Clinically, diabetic retinopathy is characterized as basement

\footnotetext{
* Correspondence: f3h@helix.nih.gov

${ }^{2}$ Ophthalmic Genetics and Visual Function Branch, National Eye Institute, $\mathrm{NIH}$, Bethesda, MD, USA

Full list of author information is available at the end of the article
}

membrane (BM) thickening, pericyte loss, endothelial cell (EC) dysfunction, microaneurysms, microvascular infarcts, and neovascularization in a patient with diabetic retinopathy $[2,3]$. Localized hypoxia has been implicated in this process, which can eventually lead to blindness. Although good glycemic control is considered to be a mainstay in preventing the vision loss, some patients with poor glycemic control do not develop retinopathy. This is well documented in the Diabetes
C Biomed Central

(c) 2010 Balasubbu et al; licensee BioMed Central Ltd. This is an Open Access article distributed under the terms of the Creative Commons Attribution License (http://creativecommons.org/licenses/by/2.0), which permits unrestricted use, distribution, and reproduction in any medium, provided the original work is properly cited. 
Control and Complications Study (DCCT) and the United Kingdom Prospective Diabetes Study (UKPDS) [4,5].

Several bio-chemical pathways have been proposed to mediate the pathogenesis of DR. These include polyol accumulation, formation of advanced glycation end products (AGEs), oxidative stress, activation of protein kinase $C$, upregulation of matrix metalloproteinases, elaboration of growth factors and secretion of adhesion molecules [6,7]. Genetic as well as environmental factors may play a crucial role in understanding the differential susceptibility to DR. To date, markers at four chromosomal loci have been linked with DR. By multipoint sib-pair analysis, loci on chromosomes 3 and 9 showed suggestive evidence for linkage to DR in American Pima Indians with type 2 diabetes yielding lod scores of 1.36 and 1.46 respectively [8]. Two other recent studies also suggested loci on chromosomes 1 and 3, and 12 with suggestive support for a number of additional loci for DR in Mexican Americans $[9,10]$.

DR shows a complex inheritance pattern, and genetic association studies are often used to identify the genetic factors influencing its development. In this context, polymorphic markers in or near several genes including aldose reductase (AKR1B1), the receptor for AGE (advanced glycation end products, $R A G E$ ), vascular endothelial growth factor (VEGF), intercellular adhesion molecule 1 (ICAM-1), pigment epithelium derived factor $(P E D F)$, hemochromatosis (HFE), and alpha2beta1 integrin have been identified as being associated with DR [11-17]. However, with the exception of VEGF, eNOS (endothelial nitric oxide synthase), IGF (insulin like growth factor), $A K R 1 B 1$ and $R A G E$, detailed investigations of most of these associations in the Indian population have not been carried out $[13,18,19,21,23]$.

Therefore, the present study aims to evaluate SNPs in nine candidate genes previously reported to be associated with DR, including the receptor for advanced glycation end products $(R A G E)$, pigment epithelium derived factor (PEDF or SERPINF1), aldose reductase (AKR1B1), erythropoietin (EPO), intercellular adhesion molecule 1 (ICAM-1), hemochromatosis (HFE), high temperature requirement $\mathrm{A} 1$ or serine peptidase (HTRA1), Complement Factor $\mathrm{H}(C F H)$ and age related maculopathy susceptibility 2 (ARMS2) to determine whether alleles of these markers are associated with DR in an Indian population.

\section{Methods}

This study protocol was approved by both the Institutional Review board and Ethics Committee of Aravind Eye Hospital, Madurai, Tamil Nadu, India and Institutional Review board of the National Eye Institute (NEI), NIH, Bethesda, Maryland. Patients were recruited from the Aravind Eye Hospital and its clinics and the laboratory part of the study was carried out at the NEI in accordance with the tenets of Declaration of Helsinki.

\section{Enrollment of cases and controls}

Patients who had T2DM (as defined by age of onset being later than 30 years of age) and exclusively used oral hypoglycemic agents were enrolled for this study from the patient population of the Aravind Eye Hospital and its outlying clinics. The criteria for diagnosis of diabetes were random blood sugars over $150 \mathrm{mgs} \%$ and HbA1C over $6 \%$. A case-control design was used with two groups of diabetic patients: an unrelated ethnically matched group of patients with DR $(\mathrm{n}=345)$ and a similar group of DNR $(n=359)$ were ascertained for the genetic association study. Patients with no signs of DR coupled with T2DM of 12-17 years duration were assigned to the DNR study group. Patients with proliferative diabetic retinopathy (PDR) as defined by eyes with definite neovascularization and/or vitreous/preretinal hemorrhages were included in the DR study group. Other patient details such as age, gender, body weight, duration of diabetes, family history of diabetes, other systemic illness, and treatment details were also documented (Table 1). They are essentially similar, although the mean duration of diabetes was slightly longer in the DNR individuals in enrollment group 2 (12 vs. 14 years). While the mean random blood sugars were slightly higher in the DR than DNR groups (212 vs. 188 and 222 vs. 102 respectively), the HbA1C values were similar (6.4 vs. 6.4 and 7.6 vs. 7.0 respectively). Statistically, the only significant differences in clinical characteristics between the DR and DNR groups overall were the percentage males $(P=0.05)$ and blood urea nitrogen $(\mathrm{P}=0.002)$.

All patients were subjected to a clinical evaluation comprising a fundus examination by a binocular indirect ophthalmoscope and a slit lamp biomicroscopic examination with a $90 \mathrm{D}$ lens in the retina clinic of Aravind Eye Hospital, Madurai, India. In addition, all patients underwent 5 -field $50^{\circ}$ color fundus photography.

The second (confirmatory) group of patients and control individuals including DR $(\mathrm{n}=100)$ and DNR $(\mathrm{n}=90)$ were similarly recruited through the Aravind Eye Hospital and its clinics and met the same diagnostic criteria as the first (exploratory) group. Ascertainment and diagnosis of patients seen at the Medical Research Foundation, Sankara Nethralaya in Chennai, India were described previously in detail [21]. Briefly, consecutive unrelated type II diabetic patients seen at the Sankara Nethralaya were tested for blood glucose and glycosylated Hb levels and a medical history including their sex, weight, duration and treatment of diabetes. Enrollment of cases and controls at the Sankara Nethralaya Hospital has been previously described 
Table 1 Clinical Characteristics of the study subjects

\begin{tabular}{|c|c|c|c|c|c|c|c|}
\hline & \multicolumn{2}{|c|}{ Patient enrollment 1} & \multicolumn{2}{|c|}{ Patient enrollment 2} & \multicolumn{2}{|c|}{ Kumaramanickavel et al. } & \multirow[b]{2}{*}{ P (DR vs. DNR)* } \\
\hline & $\begin{array}{c}\text { DR } \\
(\mathrm{n}=345)\end{array}$ & $\begin{array}{c}\text { DNR } \\
(\mathrm{n}=359) \\
\end{array}$ & $\begin{array}{c}\text { DR } \\
(n=100) \\
\end{array}$ & $\begin{array}{c}\text { DNR } \\
(n=90)\end{array}$ & $\begin{array}{c}\text { DR } \\
(n=100)\end{array}$ & $\begin{array}{c}\text { DNR } \\
(n=100)\end{array}$ & \\
\hline Males (\%) & 70.0 & 58.0 & 56.7 & 57.6 & 79 & 64 & 0.05 \\
\hline Age (Years) (Mean \pm SD) & $57 \pm 9$ & $59 \pm 11$ & $57 \pm 8$ & $58 \pm 10$ & $63 \pm 7$ & $62 \pm 7$ & 0.37 \\
\hline DM Duration ((Years) Mean \pm SD) & $14 \pm 9$ & $14 \pm 9$ & $12 \pm 6$ & $14 \pm 5$ & $17 \pm 3$ & $20 \pm 5$ & 0.42 \\
\hline $\begin{array}{l}\text { Systolic Blood pressure }(\mathrm{mmHg}) \\
\text { (Mean } \pm \text { SD) }\end{array}$ & $137 \pm 18$ & $135 \pm 18$ & $134 \pm 17$ & $128 \pm 13$ & $154 \pm 26$ & $143 \pm 21$ & 0.28 \\
\hline Diastolic Blood Pressure $(\mathrm{mmHg})($ Mean \pm SD) & $83 \pm 7$ & $82 \pm 7$ & $83 \pm 10$ & $80 \pm 10$ & $86 \pm 12$ & $81 \pm 9$ & 0.28 \\
\hline $\begin{array}{c}\text { Random Blood } \\
\text { Sugar }(\mathrm{mgs} \%)(\text { Mean } \pm \text { SD) }\end{array}$ & $212 \pm 95$ & $188 \pm 85$ & $222 \pm 93$ & $202 \pm 80$ & N/A & N/A & 0.80 \\
\hline HbA1C (\%) (Mean \pm SD) & $6.4 \pm 1.6$ & $6.4 \pm 1.2$ & $7.6 \pm 1.7$ & $7.0 \pm 1.7$ & $8.9 \pm 0.74$ & $8.2 \pm 4.8$ & 0.09 \\
\hline Serum creatinine (mgs\%) (Mean \pm SD) & $1.0 \pm 0.7$ & $0.8 \pm 0.2$ & $1.0 \pm 0.4$ & $0.8 \pm 0.3$ & N/A & N/A & 0.32 \\
\hline Blood urea (mgs\%) (Mean \pm SD) & $32 \pm 14$ & $25 \pm 8$ & $32 \pm 11$ & $27 \pm 8$ & N/A & N/A & 0.002 \\
\hline
\end{tabular}

N/A not available.

*trend test carried out on combined enrollment 1 and enrollment 2 data sets.

and essentially met the same criteria as those used at the Aravind Eye Hospital [21].

\section{Candidate gene and single nucleotide polymorphism selection}

A total of 14 SNPs and one dinucleotide repeat polymorphism in nine candidate gene regions were selected for the present study. These genes were all reported to be associated with DR in at least one population or are logical candidate genes based on the current understanding of the pathogenesis of DR. The selected SNPs are in the promoter region, 5'UTR region, or coding regions of candidate genes. The primers for selected SNPs and their corresponding genes are listed (Table S1, Additional File 1). The primers were designed for each SNP using Primer III, http://frodo.wi.mit.edu/, except for a subset of SNPs $(-374 \mathrm{~T} / \mathrm{A},-429 \mathrm{~T} / \mathrm{C}$ and rs2070600 in $R A G E$, rs35839483 in $A L R$, rs5498 in $I C A M-1$, rs1136287, rs58697961, rs12150053 and rs12948385 in $P E D F$ and rs1617640 in $E P O)$ for which the primers were chosen from previous studies $[12,14,15,23,41]$.

\section{Genotyping}

Total genomic DNA was extracted from the peripheral blood leukocytes by a salt precipitation method after obtaining written informed consent from all the participants [22]. The SNPs in the RAGE (-374 T/A, $-429 \mathrm{~T} / \mathrm{C}$ and rs2070600), PEDF (rs12150053, rs12948385, rs58697961 and rs1136287), AKR1B1 (rs35839483), EPO (rs1617640), HTRA1 (rs11200638), ICAM (rs5498), HFE (rs1800562), CFH (rs1061170 and rs3753394) and ARMS2/LOC387715 (rs10490924) were chosen on the basis of their association with DR in previous studies. SNPs were amplified by the polymerase chain reaction (PCR), (Thermocycler 9700; Applied Biosystems, Inc.
[ABI], Foster City, CA). PCR reactions were performed in $20-\mu \mathrm{L}$ reaction volumes containing $10 \mathrm{mM}$ Tris $\mathrm{HCl}$ (pH 8.9), $50 \mathrm{mM} \mathrm{KCl,} 1.5 \mathrm{mM} \mathrm{MgCl} 2,0.2 \mu \mathrm{M}$ of each primer, $250 \mu \mathrm{M}$ of each dNTP, $50 \mathrm{ng}$ of genomic DNA, and 0.5 units of Taq thermostable DNA polymerase (ABI, Foster city, CA, USA). Cycling parameters were 5 minutes at $95^{\circ} \mathrm{C}$, followed by 35 cycles of 30 seconds at $95^{\circ} \mathrm{C}, 30$ seconds at the annealing temperature $\left(\mathrm{T}_{\mathrm{m}}\right)$ of the primers $\left(52^{\circ} \mathrm{C}-63^{\circ} \mathrm{C}\right.$, see Table $\mathrm{S} 1$, Additional File 1$)$, and 45 seconds to 1 minute at $72^{\circ} \mathrm{C}$, with a final 10 minute extension at $72^{\circ} \mathrm{C}$.

Genotyping of rs1136287, rs58697961, rs12150053 and rs12948385 in PEDF, rs11200638 in HTRA1, promoter polymorphisms in $R A G E$ (-429T/C, $-374 \mathrm{~T} / \mathrm{A})$ were performed by direct sequencing (BigDye terminator chemistry, ver. 3.1; $\mathrm{ABI}$ ) using an automated DNA sequencer (Prism 3130xl; ABI, Foster city, CA, USA). Genotyping of rs1617640 in $E P O$ was carried out by Taqman real time PCR with an ABI 7900HT Fast Real-Time PCR System (ABI, Foster city, CA, USA). Genotyping of the ICAM-1 SNP rs5498 (K469E in exon 6), the HFE SNP rs1800562 (C282Y in exon 3), the CFH SNPs (rs1061170 and rs3753394), the ARMS2/LOC387715 gene SNP rs10490924 and rs2070600 in RAGE were carried out by SNaPshot PCR (ABI3100 Genetic Analyzer, ABI, Foster city, CA, USA) except for the cases studied by Kumaramanickavel et al. [21] which were genotyped by AluI RFLP analysis. Genotyping of rs35839483 in $A K R 1 B 1$ was performed using the primers described by Kumaramanickavel et al. [23] with an M13 fluorescently-labeled tail primer followed by electrophoresis on an ABI3130xl genetic analyzer (ABI, Foster city, CA, USA). It should be noted that this technique offsets the allele sizes by $19 \mathrm{bp}$. All genotypes were interpreted by 2 readers blinded to the sample phenotypes, and the results were correlated and repeated if disagreements 
could not be unambiguously resolved. All markers are in HWE overall and for cases and controls with the exception of rs2070600, which shows slight deviation ( p > 0.001 ) only in the DR samples in the confirmatory data. The confirmatory data set overall and DNR set as well as all groups in the exploratory and combined ARAVIND data sets are in HWE for all markers tested.

\section{Statistical Analysis}

Chi-square, and Fisher exact tests were used to test the allelic and genotypic associations of all the SNPs, and Hardy-Weinberg equilibrium of each SNP in control as well as in affected individuals was also examined using a $\mathrm{X}^{2}$ test, all as implemented in the Exemplar program (Sapio Sciences, Baltimore, MD) or the Golden Helix SVS software suite 7 (Golden Helix, Bozeman, MT). Odds ratio, relative risk, and call rate were also calculated using the same programs. Because this is a directed search of candidate genes with a presumed high a priori probability of being associated a P-value $<0.05$ was considered to be statistically significant. Corrections for multiple testing were done by the Bonferroni method where indicated. Association of clinical variables with DR vs. DNR was carried out using the trend test and calculated for the combined exploratory and confirmatory data sets.

\section{Results}

The clinical characteristics of the study subjects are shown in Table 1. In this study, patients with PDR as defined by eyes with definite neovascularization and/or vitreous/preretinal hemorrhages and more severe hemorrhages were selected for the DR study group and patients with no signs of DR coupled with type 2 diabetes of at least 12 years duration were selected for diabetic without retinopathy (DNR) study group. The criteria for diagnosis of diabetes were random blood sugars over $150 \mathrm{mgs} \%$ and $\mathrm{HbA1C}$ over $6 \%$. The clinical characteristics such as random blood sugars, HbA1C, blood pressure, and duration of diabetes were essentially similar in both groups, although the DR and DNR exploratory groups both had somewhat longer duration of diabetes in the report by Kumaramanickavel et al. [21] than the confirmatory groups (17 and 20 vs. 14 and 14 years, respectively). Of the clinical characteristic recorded only percentage males $(P=0.05)$ and blood urea nitrogen $(\mathrm{P}=0.002)$ were significantly associated with DR. None of the clinical characteristics other than DR were associated with any tested genotypes.

Among the 15 SNPs studied, only one, rs2070600 $(\mathrm{G}>\mathrm{A})$ in exon 3 of $R A G E$, which leads to a change of amino acid glycine to serine at codon 82 displays significant association with DR in the initial screening group (Table 2). The $\mathrm{G}$ allele $(\mathrm{P}=0.016)$, the homozygous GG
$(\mathrm{P}=0.012)$, and the heterozygous GA (P-0.011) genotypes are significantly associated with DR. Individuals with the homozygous GG genotype of this SNP have 1.78 times higher risk of developing $\mathrm{DR}(\mathrm{OR}=1.78$ : 95\% CI-1.13 - 2.82). A dominant model also shows association with $\mathrm{DR}(\mathrm{P}=0.012$, Table 3$)$, with the A allele in either heterozygous of homozygous state giving an odds ratio $(\mathrm{OR})=0.56$ with $95 \% \mathrm{CI}=0.35-0.89$. In contrast, the other RAGE gene polymorphisms tested, $-374 \mathrm{~T} / \mathrm{A}$ and $-429 \mathrm{~T} / \mathrm{C}$, do not show any significant association in this population. No other SNPs previously reported to show association could be confirmed in this population, with the possible exceptions of rs11200638 (G>A) in HTRA1 and the LOC387715 SNP rs10490924, which show marginally significant associations with DR (allelic $\mathrm{P}=0.055$ and $\mathrm{P}=0.07$, respectively).

When association of rs2070600 is tested in the confirmatory group the association is confirmed. Although the allelic association test gives only a suggestive $\mathrm{P}=0.068$ (A allele OR $=0.54: 95 \% \mathrm{CI}=0.38-0.76$ ), the whole SNP P $=0.035$ and a dominant model for the A allele gives a $\mathrm{P}=0.032$ with an $\mathrm{OR}=0.34(95 \% \mathrm{CI}=0.13$ 0.94). Combining the two groups for analysis continues to show significant association of rs2070600 with DR (allelic $\mathrm{P}<0.003)$. Similarly, the genotypic test $(\mathrm{P}=0.003)$, the dominant model $(\mathrm{P}=0.0013$, $\mathrm{OR}=0.51$, $95 \% \mathrm{CI}=0.34-0.82)$ and the additive model $(\mathrm{P}=0.003)$ all show significant association (Table 4).

The $R A G E$ gene was selected as a candidate based on previous analysis showing association in an Indian population by Kumaramanickavel et al [21]. Because of the ethnic and clinical similarities between the ARAVIND and Sankara Nethralaya study populations (Table 1) and because they represented the only two studies examining $R A G E$ gene polymorphisms in the Indian population, we decided to combine data from the two studies in a single analysis. It was noted that our results for the $R A G E$ gene were remarkably similar to those reported by Kumaramanickavel et al. [21] with major allele frequencies of .95 vs. .95 and .92 vs. .89 for the DR and DNR groups, respectively. The combined results once more confirmed association of the $G$ allele with DR: allelic $\mathrm{P}<0.0003$ with the A allele $\mathrm{OR}=0.54(0.38-$ 0.76). The whole SNP association is also significant with a $\mathrm{P}=0.0003$, as are the results of analysis under specific models with the A allele dominant $\mathrm{P}=0.00011$ with an $\mathrm{OR}=0.49(95 \% \mathrm{CI}=0.34-0.7)$ and the additive model $\mathrm{P}=0.00047$ (Table 4).

None of the remaining SNPs, including, four SNPs rs1136287 (C/T), rs58697961 (G/A), rs12150053 (T/C) and rs12948385 (G/A) in the PEDF gene, rs1617640 $(\mathrm{G} / \mathrm{T})$ in $E P O$, rs1800562 (G/A) in HFE, rs5498 (A/G) in $I C A M, \mathrm{rs} 1061170$ and rs3753394 in $C F H$, rs10490924 in ARMS2/LOC387715 and rs35839483 (CA)n in AKR1B1 
Table 2 Allele and Genotype distribution of Nine candidate gene polymorphisms in the study

\begin{tabular}{|c|c|c|c|c|c|c|c|c|c|c|c|}
\hline Gene & SNP & Allele & DR & DNR & $\begin{array}{c}\text { Odds ratio } \\
(95 \% \mathrm{Cl})\end{array}$ & $\mathbf{P}$ & Genotype & $\begin{array}{c}\text { DR } \\
(n=345)\end{array}$ & $\begin{array}{c}\text { DNR } \\
(n=359)\end{array}$ & $\begin{array}{l}\text { Odds ratio } \\
(95 \% \mathrm{Cl}) \wedge\end{array}$ & $P$ \\
\hline \multirow[t]{8}{*}{ RAGE } & $(-374 \mathrm{~T} / \mathrm{A})$ & $\mathrm{T}$ & $98.10 \%$ & $98.52 \%$ & $0.77(0.27-2.15)$ & 0.62 & $\pi$ & $96.21 \%$ & $97.05 \%$ & $0.76(0.27-2.13)$ & 0.62 \\
\hline & & A & $1.89 \%$ & $1.48 \%$ & & & TA & $3.79 \%$ & $2.95 \%$ & $1.29(0.46-3.63)$ & 0.62 \\
\hline & (- 429T/C) & T & $86.26 \%$ & $83.76 \%$ & $1.22(0.84-1.76)$ & 0.29 & $\pi$ & $74.88 \%$ & $71.31 \%$ & $1.19(0.78-1.82)$ & 0.39 \\
\hline & & C & $13.74 \%$ & $16.24 \%$ & & & $\mathrm{TC}$ & $22.75 \%$ & $24.89 \%$ & $0.88(0.57-1.37)$ & 0.59 \\
\hline & & & & & & & CC & $2.37 \%$ & $3.80 \%$ & $0.61(0.20-1.86)$ & 0.38 \\
\hline & rs2070600 & G & $95.1 \%$ & $91.9 \%$ & $1.7(1.1-2.6)$ & $0.016^{*}$ & GG & $90.4 \%$ & $84.1 \%$ & $1.78(1.13-2.82)$ & $0.012^{*}$ \\
\hline & & A & $4.9 \%$ & $8.1 \%$ & & & GA & $9.3 \%$ & $15.6 \%$ & $0.55(0.35-0.88)$ & $0.011^{*}$ \\
\hline & & & & & & & AA & $0.3 \%$ & $0.3 \%$ & $1.04(0.06-16.7)$ & $0.97^{*}$ \\
\hline \multirow[t]{12}{*}{ PEDF } & rs12150053 & T & $77.86 \%$ & $76.06 \%$ & $1.10(0.80-1.51)$ & 0.52 & $\pi$ & $60.95 \%$ & $58.12 \%$ & $1.12(0.76-1.64)$ & 0.54 \\
\hline & & C & $22.14 \%$ & $23.94 \%$ & & & $\mathrm{TC}$ & $33.81 \%$ & $35.90 \%$ & $0.91(0.61-1.34)$ & 0.64 \\
\hline & & & & & & & CC & $5.24 \%$ & $5.98 \%$ & $1.04(0.06-1.95)$ & 0.73 \\
\hline & rs12948385 & G & $78.33 \%$ & $80.17 \%$ & $0.89(0.64-1.23)$ & 0.49 & GG & $62.38 \%$ & $66.67 \%$ & $0.82(0.56-1.22)$ & 0.34 \\
\hline & & A & $21.67 \%$ & $19.83 \%$ & & & GA & $31.90 \%$ & $27 \%$ & $1.26(0.84-1.90)$ & 0.25 \\
\hline & & & & & & & $A A$ & $5.71 \%$ & $6.33 \%$ & $0.89(0.40-1.96)$ & 0.78 \\
\hline & rs58697961 & G & $50.47 \%$ & $51.90 \%$ & $0.94(0.72-1.22)$ & 0.67 & GG & $27.01 \%$ & $26.58 \%$ & $1.02(0.67-1.55)$ & 0.91 \\
\hline & & A & $49.53 \%$ & $48.10 \%$ & & & GA & $46.92 \%$ & $50.63 \%$ & $0.86(0.59-1.24)$ & 0.43 \\
\hline & & & & & & & AA & $26.07 \%$ & $22.78 \%$ & $1.19(0.77-1.84)$ & 0.41 \\
\hline & rs1136287 & C & $58.17 \%$ & $54.03 \%$ & $1.18(0.90-1.54)$ & 0.21 & CC & $34.13 \%$ & $28.40 \%$ & $1.30(0.87-1.95)$ & 0.19 \\
\hline & & T & $41.83 \%$ & $45.97 \%$ & & & $\mathrm{CT}$ & $48.08 \%$ & $51.27 \%$ & $0.88(0.60-1.27)$ & 0.5 \\
\hline & & & & & & & $\pi$ & $17.79 \%$ & $20.33 \%$ & $0.84(0.52-1.36)$ & 0.49 \\
\hline \multirow[t]{3}{*}{ HTRA1 } & rs11200638 & G & $61.7 \%$ & $70 \%$ & $0.68(0.45-1.01)$ & 0.055 & GG & $39.34 \%$ & $47.68 \%$ & $0.64(0.37-1.1)$ & 0.11 \\
\hline & & A & $38.3 \%$ & $30.0 \%$ & & & GA & $46.92 \%$ & $43.04 \%$ & $1.18(0.69-2.04)$ & 0.53 \\
\hline & & & & & & & $A A$ & $13.74 \%$ & $9.28 \%$ & $1.86(0.8-4.3)$ & 0.14 \\
\hline \multirow[t]{3}{*}{ EPO } & rs1617640 & G & $67.30 \%$ & $67.72 \%$ & $0.98(0.74-1.29)$ & 0.89 & GG & $43.60 \%$ & $43.88 \%$ & $0.98(0.68-1.43)$ & 0.95 \\
\hline & & T & $32.70 \%$ & $32.28 \%$ & & & GT & $47.39 \%$ & $47.68 \%$ & $0.98(0.68-1.43)$ & 0.95 \\
\hline & & & & & & & $\pi$ & $9 \%$ & $8.44 \%$ & $1.07(0.55-2.07)$ & 0.83 \\
\hline \multirow[t]{3}{*}{ ICAM } & rs5498 & A & $53.42 \%$ & $51.91 \%$ & $1.06(0.81-1.39)$ & 0.66 & AA & $30 \%$ & $27.66 \%$ & $1.12(0.73-1.70)$ & 0.59 \\
\hline & & G & $46.58 \%$ & $48.08 \%$ & & & $A G$ & $46.84 \%$ & $48.51 \%$ & $0.93(0.63-1.37)$ & 0.73 \\
\hline & & & & & & & GG & $23.16 \%$ & $23.83 \%$ & $0.96(0.61-1.51)$ & 0.87 \\
\hline \multirow[t]{6}{*}{$\mathrm{CFH}$} & rs3753394 & T & $72.03 \%$ & $69.49 \%$ & $1.13(0.83-1.53)$ & 0.42 & $\pi$ & $55.36 \%$ & $49.15 \%$ & $1.28(0.86-1.89)$ & 0.21 \\
\hline & & C & $27.97 \%$ & $30.51 \%$ & & & $\mathrm{CT}$ & $33.33 \%$ & $40.68 \%$ & $0.72(0.48-1.09)$ & 0.12 \\
\hline & & & & & & & $C C$ & $11.30 \%$ & $10.17 \%$ & $1.12(0.60-2.10)$ & 0.71 \\
\hline & rs1061170 & C & $69.86 \%$ & $72.25 \%$ & $0.89(0.66-1.19)$ & 0.43 & $\mathrm{CC}$ & $48.33 \%$ & $50 \%$ & $0.93(0.64-1.35)$ & 0.72 \\
\hline & & T & $30.14 \%$ & $27.75 \%$ & & & $\mathrm{CT}$ & $43.06 \%$ & $44.49 \%$ & $0.94(0.64-1.37)$ & 0.76 \\
\hline & & & & & & & $\pi$ & $8.61 \%$ & $5.50 \%$ & $1.61(0.77-3.38)$ & 0.19 \\
\hline \multirow[t]{3}{*}{ LOC387715 } & rs10490924 & T & $62.57 \%$ & $68.43 \%$ & $0.77(0.57-1.02)$ & 0.07 & $\pi$ & $38.55 \%$ & $47.03 \%$ & $0.70(0.47-1.04)$ & 0.08 \\
\hline & & G & $37.43 \%$ & $31.57 \%$ & & & $\mathrm{TG}$ & $48.04 \%$ & $42.80 \%$ & $1.23(0.83-1.82)$ & 0.28 \\
\hline & & & & & & & GG & $13.41 \%$ & $10.17 \%$ & $1.36(0.74-2.49)$ & 0.3 \\
\hline
\end{tabular}

Chi-square test was used to compare the genotype and allele frequencies between cases and controls.

The SNPs are in Hardy-weinberg equilibrium.

${ }^{*}$ P-Value $<0.05$ is considered to be statistically significant.

$\wedge$ The odds ratio for one genotype was calculated against the other two genotypes combined.

showed significant association with DR. The SNP rs1800562 (G/A) in HFE was found not to be polymorphic in the study groups. Additionally, 12 alleles 138 bps-162 bps in rs35839483 (CA)n were identified. The allele frequencies of the $A K R 1 B 1$ (CA)n dinucleotide repeat polymorphism are given in Table 5 . None of the alleles show significant association with DR in this population.

\section{Discussion}

The present study evaluates the potential association of fifteen polymorphisms in nine previously identified DR candidate genes with type 2 diabetes patients in a South Indian population. In this case-controlled study only one SNP, rs2070600 in the RAGE gene, could be shown to be significantly associated with retinopathy in the presence of DR. Because of the relatively small number 
Table 3 Analysis of RAGE under various models in the exploratory and confirmatory sets

\begin{tabular}{|c|c|c|c|c|c|c|c|c|c|}
\hline Gene & SNP & Allele & DR & DNR & $\begin{array}{l}\text { Odds ratio } \\
(95 \% \mathrm{Cl})\end{array}$ & $\mathbf{P}$ & Model & $\begin{array}{l}\text { Odds ratio } \\
(95 \% \mathrm{Cl})\end{array}$ & $P$ \\
\hline \multirow[t]{2}{*}{ RAGE } & rs2070600 & G & $95.1 \%$ & $91.9 \%$ & $1.7(1.1-2.6)$ & $0.016^{2}$ & SNP & & $0.04^{2}$ \\
\hline & & A & $4.9 \%$ & $8.1 \%$ & $0.59(0.38-0.91)$ & & $\begin{array}{l}\text { Dominant } \\
\text { Additive }\end{array}$ & $\begin{array}{c}\mathrm{OR}=0.56(0.35-0.89)^{1} \\
\mathrm{R}=-0.091\end{array}$ & $\begin{array}{l}0.012^{2} \\
0.016^{3}\end{array}$ \\
\hline
\end{tabular}

${ }^{1}(\mathrm{AA}, \mathrm{AG}) / \mathrm{AA}$.

${ }^{2} \chi^{2}, P$-Value $<0.05$ is considered to be statistically significant.

${ }^{3}$ Trend, P-Value $<0.05$ is considered to be statistically significant.

Genotype and allele frequencies of RAGE in the confirmatory set

\begin{tabular}{|c|c|c|c|c|c|c|c|c|c|}
\hline Gene & SNP & Allele & DR & DNR & $\begin{array}{l}\text { Odds ratio } \\
(95 \% \mathrm{Cl})\end{array}$ & $\mathbf{P}$ & Model & $\begin{array}{c}\text { Odds ratio/R } \\
(95 \% \mathrm{Cl})\end{array}$ & $P$ \\
\hline \multirow[t]{3}{*}{ RAGE } & rs 2070600 & G & $96.5 \%$ & $92.2 \%$ & $1.78(1.22-2.60)$ & 0.068 & SNP & & $0.035^{2}$ \\
\hline & & A & $3.5 \%$ & $7.8 \%$ & $0.54(0.38-0.76)$ & & Dominant & $\mathrm{OR}=0.34(0.13-0.94)^{1}$ & $0.032^{2}$ \\
\hline & & & & & & & Additive A & $R=-0.129$ & $0.07^{3}$ \\
\hline
\end{tabular}

*includes the exploratory, confirmatory sets and that of Kumaramanickavel et al.

${ }^{1}(\mathrm{AA}, \mathrm{AG}) / \mathrm{AA}$.

${ }^{2} \chi^{2}, \mathrm{P}$-Value $<0.05$ is considered to be statistically significant.

${ }^{3}$ Trend, P-Value $<0.05$ is considered to be statistically significant (not corrected for multiple testing).

of patients and controls analyzed, this study cannot necessarily exclude the possibility of alleles of the remaining SNPs showing some association with DR, especially those in HTRA1 and LOC387715. However, it is unlikely that the level of association would be greater than the $95 \%$ confidence limits of the odds ratios shown in Table 3, which are generally less than 1.5 for allelic association with the exception of the $R A G E$ related SNPs, and less than 2-2.5 for the genotype odds ratios. Finally, it is possible that associations seen in other populations might not be present in southern Indians because of different population histories, which could alter haplotype block structure and thus non-causative allelic association, and possibly differing genetic and environmental contributions to the disease risk in various ethnic and geographic groups. In addition, this study did not address the use of oral hypoglycemic agents on the development of DR directly. However, since the main effects of these agents would be expected to result from their enhancement of glycemic control, to some extent one might expect their effects to be reflected in the fasting blood glucose and HbA1C levels, which were similar in the DR and DNR subjects.

$R A G E$ gene polymorphisms are attractive candidates to influence DR because of pathophysiological data correlating retinopathy and advanced glycation end products (AGEs). RAGE, which maps to chromosome 6p21.3, is a member of the immunoglobulin super family. AGEs result from the non-enzymatic glycation of proteins and lipids. They are found at increased levels in diabetes and

Table 4 Analysis of combined sets under various models

\begin{tabular}{|c|c|c|c|c|c|c|c|c|c|}
\hline \multicolumn{10}{|c|}{ Genotype and allele frequencies of RAGE gene polymorphism rs 2070600 in the exploratory and confirmatory sets combined } \\
\hline Gene & SNP & Allele & DR & DNR & $\begin{array}{l}\text { Odds ratio } \\
(95 \% \mathrm{Cl})\end{array}$ & $\mathbf{P}$ & Model & $\begin{array}{l}\text { Odds ratio } \\
(95 \% \mathrm{Cl})\end{array}$ & $\mathbf{P}$ \\
\hline \multirow[t]{3}{*}{ RAGE } & rs 2070600 & G & $95.4 \%$ & $92 \%$ & $1.8(1.2-2.7)$ & $0.003^{2}$ & SNP & & $0.003^{2}$ \\
\hline & & A & $4.6 \%$ & $8 \%$ & $0.55(0.37-0.82)$ & & Dominant & $0.51(0.34-0.77)^{1}$ & $0.0013^{2}$ \\
\hline & & & & & & & Additive & $R=-0.0997$ & $0.003^{3}$ \\
\hline
\end{tabular}

Genotype and allele frequencies of RAGE in all sets combined*

\begin{tabular}{|c|c|c|c|c|c|c|c|c|c|}
\hline Gene & SNP & Allele & DR & DNR & $\begin{array}{l}\text { Odds ratio } \\
(95 \% \mathrm{Cl})\end{array}$ & $\mathbf{P}$ & Model & $\begin{array}{c}\text { Odds ratio/R } \\
(95 \% \mathrm{Cl})\end{array}$ & $\mathbf{P}$ \\
\hline \multirow[t]{3}{*}{ RAGE } & rs2070600 & G & $95.2 \%$ & $91.4 \%$ & $1.78(1.22-2.60)$ & $0.0003^{*}$ & SNP & & $0.0003^{2}$ \\
\hline & & A & $4.8 \%$ & $8.6 \%$ & $0.54(0.38-0.76)$ & & Dominant & $0.49(0.34-0.70)^{1}$ & $0.00011^{2}$ \\
\hline & & & & & & & Additive A & $R=-0.10548$ & $0.00047^{3}$ \\
\hline
\end{tabular}

*includes the exploratory, confirmatory sets and that of Kumaramanickavel et al.

${ }^{1}$ (AA,AG)/AA.

${ }^{2} \chi^{2}, \mathrm{P}$-Value $<0.05$ is considered to be statistically significant.

${ }^{3}$ Trend, P-Value $<0.05$ is considered to be statistically significant (not corrected for multiple testing). 
Table 5 Allele frequencies of ALR2 (CA)n polymorphism

\begin{tabular}{lllll}
\hline Allele & DR $(\mathbf{n}=$ & $\begin{array}{l}\text { DNR }(\mathbf{n}= \\
\mathbf{4 2 2})\end{array}$ & $\begin{array}{l}\text { Odd4) } \\
\text { Cl) }\end{array}$ & $\begin{array}{l}\text { Patio (95\% } \\
\text { P-Value }\end{array}$ \\
\hline 138 & 0 & $3(0.63 \%)$ & $\infty$ & $0.1<\mathrm{p}<0.25$ \\
140 & $4(0.94 \%)$ & $8(1.68 \%)$ & $0.55(0.16-1.86)$ & $0.5<\mathrm{p}<0.25$ \\
142 & $1(0.23 \%)$ & 0 & $\infty$ & $0.5<\mathrm{p}<0.25$ \\
146 & $3(0.71 \%)$ & 0 & $\infty$ & $0.1<\mathrm{p}<0.05$ \\
148 & $20(4.73 \%)$ & $16(3.37 \%)$ & $1.424(0.72-2.78)$ & $0.5<\mathrm{p}<0.25$ \\
150 & $73(17.29 \%)$ & $65(13.71 \%)$ & $1.316(0.91-1.89)$ & $0.75<\mathrm{p}<0.5$ \\
152 & $189(44.78 \%)$ & $216(45.56 \%)$ & $0.96(0.74-1.26)$ & $0.9<\mathrm{p}<0.75$ \\
154 & $55(13.03 \%)$ & $65(13.71 \%)$ & $0.94(0.64-1.38)$ & $0.9<\mathrm{p}<0.75$ \\
156 & $41(9.71 \%)$ & $43(9.07 \%)$ & $1.07(0.68-1.69)$ & $0.9<\mathrm{p}<0.75$ \\
158 & $23(5.45 \%)$ & $39(8.22 \%)$ & $0.64(0.37-1.09)$ & $0.1<\mathrm{p}<0.25$ \\
160 & $11(2.60 \%)$ & $19(4 \%)$ & $0.64(0.30-1.36)$ & $0.1<\mathrm{p}<0.25$ \\
162 & $2(0.47 \%)$ & 0 & $\infty$ & $0.1<\mathrm{p}<0.25$ \\
\hline
\end{tabular}

can lead to increased oxidative stress and receptormediated activation and secretion of various cytokines $[24,25]$. Accumulation of AGEs has been suggested to contribute to vasculopathy by increasing retinal endothelial cell permeability [26]. Specific AGE-binding receptors include the AGE-receptor complex, the macrophage scavenger receptors, and the receptor for AGE (RAGE). A Gly82Ser polymorphism in $R A G E$ is potentially interesting since it occurs at a predicted $\mathrm{N}$-linked glycosylation motif in the AGE binding site, thereby influencing AGERAGE interactions [12]. Kumaramanickavel et al. [21] previously reported that this polymorphism is associated with decreased risk for the development of DR in a Southern Indian population essentially similar to the one studied here. However, additional studies investigating the same locus did not show significant association for this polymorphism in Chinese and Japanese populations $[20,27]$, and a recent study showed association of the A allele (serine) with DR in a Han Chinese population [28]. Association of the opposite allele of a polymorphism with disease has been reported before, and an additional example with an elegant theoretical analysis of possible causes for this has been presented by Lin et al. [29,30]. As also suggested by Zhang et al. [28] in their report, this might represent either different molecular pathogenesis of the disease in the two populations or simply a different population history resulting in different haplotype structure of the associated region. A particularly interesting example is that of the LOXL1 polymorphisms rs3825942 and rs1048661, which are in linkage disequilibrium and both show association with exfoliative glaucoma (XFG) $[31,32]$. While the $G$ allele of rs3825942 is associated with XFG in both Caucasian and Japanese populations, the $G$ allele of rs1048661 (GG haplotype of rs1048661 and rs3825942) is associated with XFG in Caucasians but the T allele (TG haplotype of rs1048661 and rs3825942) is associated with XFG in Japanese.
Our study supports association of the 82Gly allele and DR $(\mathrm{P}=0.0003)$ with an odds ratio of 0.54 (95\% confidence interval $=0.38-0.76)$ for the $82 \operatorname{Ser}(\mathrm{A})$ allele in a southern Indian population. Although the AA genotype appears to have an increased OR in the exploratory cohort (1.04, Table 2), this is due to the presence of a single AA individual in both the DR and DNR groups and probably represents a chance variation. Overall, the risk for DR decreases with the number of 82Ser (A) alleles, with both the additive model and dominant models supporting association. This supports the original findings of Kumaramanickavel et al. that 82Ser is a protective allele for diabetic retinopathy in the Indian population, and the similarities between the study populations in terms of ethnic origin and clinical criteria suggested that results from the subjects of both studies might be combined in a single analysis $[21,33]$. The individuals in the study by Kumaramanickavel et al. [21] were slightly older (63 years vs. 57 years average), had a slightly longer history of diabetes (18 years vs. 14 years average) and had somewhat higher HbA1C values (8.5 vs. 6.4 average). However, the similarities in the diagnostic and exclusion criteria and particularly the Indian ethnic composition of both groups allowed a combined analysis. The combined analysis was consistent with the results of subjects recruited from both hospitals, giving a similar odds ratios for the $G$ allele (1.8 vs. 1.7$)$, in the combined and ARAVIND patients respectively. The combined results, however, showed increased significance, with improvements in both the allelic (0.0003 vs. $0.003)$ whole SNP genotypic (0.0003 vs. 0.003$)$ dominant $(0.00011$ vs 0.0013$)$ and additive $(0.00047$ vs. 0.003$)$ $\mathrm{p}$-values in the combined and Aravind groups respectively. While we have not included a Bonferroni correction directly because of uncertainty about the a priori likelihood of each locus being true, a Bonferroni correction for multiple testing considering tests for 15 markers were performed might be a $\mathrm{P}<0.0033$, which is met in the combined ARAVIND and the final combined data sets.

In contrast to the results with rs2070600, neither the $-374 \mathrm{~T} / \mathrm{A}$ SNP nor the $-429 \mathrm{~T} / \mathrm{C}$ SNP in $R A G E$ were found to be associated with DR, even though this association had been reported in the British population [34]. This might reflect population differences in the pathogenesis of DR in the Indian and other populations, but might also be a reflection of the relatively low minor allele frequencies in the Indian population, as the $95 \%$ confidence intervals for these SNPs, and especially -374 $\mathrm{T} / \mathrm{A}$, are very wide.

A putative transcription factor binding site of the HTRA1 gene in the $10 \mathrm{q} 26$ region was shown to confer significant risk for choroidal neovascularization in age related macular degeneration (AMD) and SNPs 
rs1061170, rs3753394 in $C F H$ and rs10490924 in ARMS2/LOC387715 showed significant association [35-40]. Because neovascularization is common to both AMD and DR, we hypothesized that these genes may play a role in DR. To the best of our knowledge, this is the first report correlating the association of these SNPs with DR (however, our results indicate only marginal significance of the SNP rs11200638 in HTRA1 gene with DR).

We have attempted to avoid population substructure in our study. However, it remains possible that the positive and negative results could potentially be due to subtle population stratification and should be taken as suggestive rather than definitive.

\section{Conclusion}

In conclusion, we are able to confirm association of the G82S polymorphism of $R A G E$ with diabetic retinopathy in the population of southern India. We studied the association of SNPs rs11200638 in the HTRA1 gene, rs1061170, rs3753394 in $C F H$ and rs10490924 in ARMS2/LOC387715 with DR for the first time. Our findings suggest that these three polymorphisms may not be associated with DR in the southern Indian population. Our data also strongly suggest that patients with the serine allele of the Gly82Ser (rs2070600) polymorphism in the RAGE gene show a decreased risk for diabetic retinopathy in the Indian population, although association of this allele with DR in a Chinese population suggests that this might represent linkage disequilibrium with a nearby causative rather than implying that glycation at this site plays a directly causative role in the development of diabetic retinopathy.

\begin{abstract}
Abbreviations
DR: Diabetic Retinopathy; DM: Diabetes Mellitus; T2DM: Type 2 Diabetes Mellitus; DNR: Diabetic patients without retinopathy; SNPs: Single Nucleotide Polymorphisms; RAGE: Receptor for Advanced Glycation End Products; PEDF: Pigment Epithelium Derived Factor; AKR1B1: Aldose Reductase; CFH: Complement Factor H; ARMS2: Age Related Maculopathy Susceptibility 2; EPO: Erythropoietin; HTRA1: High Temperature Requirement A1; ICAM: Intercellular Adhesion Molecule1; HFE: Hemochromatosis; OR: Odds Ratio.
\end{abstract}

\footnotetext{
Acknowledgements

The authors like to thank all the participants for their kind cooperation in this study. The authors also acknowledge the support extended by the National Eye Institute, NIH for providing pre-doctoral fellowship, TIFAC-CORE in Diabetic Retinopathy and Counsil of Scientific and Industrial Research for technical and financial support. We thank Dr. VR. Muthukkaruppan, director of research, Aravind Medical Research Foundation, for providing valuable suggestions; we also thank Dr. G. Kumaramanickavel, advisor of research in Narayana Nethralaya, Bangalore and Aditya Jyot Eye Hospital, Mumbai and Dr S Uthra for their help with the combined analysis, providing valuable suggestions and reviewing the manuscript. Finally we would like to thank Dr. S. Senthilkumari for a close reading of the manuscript and Drs. S. Daiger (UTHSC, Houston) and Lijia Chen (Chinese University of Hong Kong) for helpful discussions regarding inverse association and VR.Muthulakshmi, T.P. Vasanthi, A.Gomathy, D.Muthuselvi for their help in samples collection.
}

\section{Author details}

${ }^{1}$ Aravind Medical Research Foundation, Dr. G. Venkataswamy Eye Research Institute, Aravind Eye Hospital, \#1, Anna Nagar, Madurai -625 020, India. ${ }^{2}$ Ophthalmic Genetics and Visual Function Branch, National Eye Institute, $\mathrm{NIH}$, Bethesda, MD, USA. ${ }^{3}$ Retina Clinic, Aravind Eye Hospital, \#1, Anna Nagar, Madurai -625 020, India. ${ }^{4}$ Ophthalmic Genetics and Visual Function Branch, National Eye Institute, NIH, 5635 Fisher's Lane, Rockville, MD 20852, USA.

\section{Authors' contributions}

SB performed the sample collection, genotyping, statistical analysis, interpreted the data and drafted the manuscript. PS was involved in the study design and critically reading the manuscript. AR, KR and NP recruited and clinically characterized study subjects. GG was involved in genotyping of newly recruited samples. JFH was involved in the study design, data analysis, interpretation of the data, and preparation of the final version of the manuscript. All authors read and approved the final manuscript.

\section{Competing interests}

The authors declare that they have no competing interests.

Received: 20 March 2010 Accepted: 10 November 2010 Published: 10 November 2010

\section{References}

1. Resnikoff S: Global data on visual impairment in the year 2002. Bulletin of the World Health Organization 2004, 82:844-851.

2. Klein R, Klein BE, Moss SE, Davis MD, DeMets DL: The Wisconsin epidemiologic study of diabetic retinopathy. III. Prevalence and risk of diabetic retinopathy when age at diagnosis is 30 or more years. Arch Ophthalmol 1984, 102:527-532.

3. Patz A: Studies on retinal neovascularization. Friedenwald Lecture. Invest Ophthalmol Vis Sci 1980, 19:1133-1138.

4. The absence of a glycemic threshold for the development of long-term complications: the perspective of the Diabetes Control and Complications Trial. Diabetes 1996, 45:1289-1298.

5. Intensive blood-glucose control with sulphonylureas or insulin compared with conventional treatment and risk of complications in patients with type 2 diabetes (UKPDS 33). UK Prospective Diabetes Study (UKPDS) Group. Lancet 1998, 352:837-853.

6. Sulochana KN, Ramakrishnan S, Rajesh M, Coral K, Badrinath SS: Diabetic retinopathy: Molecular mechanisms, present regime of treatment and future prospectives. Current Science 2001, 80:133-142.

7. Fong DS, Aiello LP, Ferris FL, Klein R: Diabetic retinopathy. Diabetes Care 2004, 27:2540-2553.

8. Imperatore G, Hanson RL, Pettitt DJ, Kobes S, Bennett PH, Knowler WC, Pima Diabetes Genes Group: Sib-pair linkage analysis for susceptibility genes for microvascular complications among Pima Indians with type 2 diabetes. Diabetes 1998, 47:821-830.

9. Looker HC, Nelson RG, Chew E, Klein R, Klein BE, Knowler WC, Hanson RL: Genome-wide linkage analyses to identify Loci for diabetic retinopathy. Diabetes 2007, 56:1160-1166.

10. Hallman DM, Boerwinkle E, Gonzalez VH, Klein BE, Klein R, Hanis CL: A genome-wide linkage scan for diabetic retinopathy susceptibility genes in Mexican Americans with type 2 diabetes from Starr County, Texas. Diabetes 2007, 56:1167-1173.

11. Petrovic $M G$, Peterlin $B$, Hawlina M, Petrovic D: Aldose reductase (AC)n gene polymorphism and susceptibility to diabetic retinopathy in Type 2 diabetes in Caucasians. J Diabetes Complications 2005, 19:70-73.

12. Hudson Bl, Stickland MH, Grant PJ: Identification of polymorphisms in the receptor for advanced glycation end products (RAGE) gene: prevalence in type 2 diabetes and ethnic groups. Diabetes 1998, 47:1155-1157.

13. Suganthalakshmi B, Anand R, Kim R, Mahalakshmi R, Karthikprakash S, Namperumalsamy P, Sundaresan P: Association of VEGF and eNOS gene polymorphisms in type 2 diabetic retinopathy. Mol Vis 2006, 12:336-341

14. Liu L, Yu Q, Wang H, Zhang SX, Huang C, Chen X: Association of intercellular adhesion molecule 1 polymorphisms with retinopathy in Chinese patients with Type 2 diabetes. Diabet Med 2006, 23:643-648.

15. lizuka H, Awata T, Osaki M, Neda T, Kurihara S, Inoue K, Inukai K, Kabasawa S, Mori K, Yoneya S, Katayama S: Promoter polymorphisms of 
the pigment epithelium-derived factor gene are associated with diabetic retinopathy. Biochem Biophys Res Commun 2007, 361:421-426.

16. Peterlin B, Globocnik PM, Makuc J, Hawlina M, Petrovic D: A hemochromatosis-causing mutation $\mathrm{C} 282 \mathrm{Y}$ is a risk factor for proliferative diabetic retinopathy in Caucasians with type 2 diabetes. $J$ Hum Genet 2003, 48:646-649.

17. Matsubara Y, Murata M, Maruyama T, Handa M, Yamagata N, Watanabe G, Saruta T, Ikeda Y: Association between diabetic retinopathy and genetic variations in alpha2beta1 integrin, a platelet receptor for collagen. Blood 2000, 95:1560-1564.

18. Uthra S, Raman R, Mukesh BN, Padmaja Kumari R, Paul PG, Lakshmipathy P, Gnanamoorthy P, Sharma T, McCarty CA, Kumaramanickavel G: Intron 4 VNTR of endothelial nitric oxide synthase (eNOS) gene and diabetic retinopathy in type 2 patients in southern India. Ophthalmic Genet 2007, 28:77-81.

19. Uthra S, Raman R, Mukesh BN, Rajkumar SA, Kumari RP, Agarwal S, Paul PG, Lakshmipathy P, Gnanamoorthy P, Sharma T, McCarty CA, Kumaramanickavel G: Diabetic retinopathy and IGF-1 gene polymorphic cytosine-adenine repeats in a Southern Indian cohort. Ophthalmic Res 2007, 39:294-299.

20. Liu L, Xiang K: RAGE Gly82Ser polymorphism in diabetic microangiopathy. Diabetes Care 1999, 22:646.

21. Kumaramanickavel G, Ramprasad VL, Sripriya S, Upadyay NK, Paul PG, Sharma T: Association of Gly82Ser polymorphism in the RAGE gene with diabetic retinopathy in type II diabetic Asian Indian patients. J Diabetes Complications 2002, 16:391-394.

22. Miller SA, Dykes DD, Polesky HF: A simple salting out procedure for extracting DNA from human nucleated cells. Nucleic Acids Res 1988, $16: 1215$.

23. Kumaramanickavel G, Sripriya S, Ramprasad VL, Upadyay NK, Paul PG, Sharma T: Z-2 aldose reductase allele and diabetic retinopathy in India. Ophthalmic Genet 2003, 24:41-48.

24. Brownlee M, Cerami A, Vlassara H: Advanced glycosylation end products in tissue and the biochemical basis of diabetic complications. $N$ Engl J Med 1988, 318:1315-1321.

25. Schmidt AM, Yan SD, Wautier JL, Stern D: Activation of receptor for advanced glycation end products: a mechanism for chronic vascular dysfunction in diabetic vasculopathy and atherosclerosis. Circ Res 1999, 84:489-497.

26. Vlassara H, Bucala R, Striker L: Pathogenic effects of advanced glycosylation: biochemical, biologic, and clinical implications for diabetes and aging. Lab Invest 1994, 70:138-151.

27. Yoshioka K, Yoshida T, Takakura Y, Umekawa T, Kogure A, Toda H Yoshikawa T: Relation between polymorphisms G1704T and G82S of rage gene and diabetic retinopathy in Japanese type 2 diabetic patients. Intern Med 2005, 44:417-421.

28. Zhang HM, Chen LL, Wang L, Liao YF, Wu ZH, Ye F, Xu S, Yi LL: Association of $1704 \mathrm{G} / \mathrm{T}$ and $\mathrm{G} 82 \mathrm{~S}$ polymorphisms in the receptor for advanced glycation end products gene with diabetic retinopathy in Chinese population. J Endocrinol Invest 2009, 32:258-262.

29. Srinivasan SR, Li S, Chen W, Tang R, Bond MG, Boerwinkle E, Berenson GS: Q192R polymorphism of the paraoxanase 1 gene and its association with serum lipoprotein variables and carotid artery intima-media thickness in young adults from a biracial community. The Bogalusa Heart Study. Atherosclerosis 2004, 177:167-174.

30. Lin PI, Vance JM, Pericak-Vance MA, Martin ER: No gene is an island: the flip-flop phenomenon. Am J Hum Genet 2007, 80:531-538.

31. Mori K, Imai K, Matsuda A, Ikeda Y, Naruse S, Hitora-Takeshita H, Nakano M, Taniguchi T, Omi N, Tashiro K, Kinoshita S: LOXL1 genetic polymorphisms are associated with exfoliation glaucoma in the Japanese population. Mol Vis 2008, 14:1037-1040.

32. Fuse N, Miyazawa A, Nakazawa T, Mengkegale M, Otomo T, Nishida K: Evaluation of LOXL1 polymorphisms in eyes with exfoliation glaucoma in Japanese. Mol Vis 2008, 14:1338-1343.

33. Brahmachari SK, Majumder PP, Mukerii M, Habib S, Dash D, Ray K, et al: Indian Genome Variation Consortium: Genetic landscape of the people of India: a canvas for disease gene exploration. J Genet 2008, 87:3-20.

34. Hudson BI, Stickland MH, Futers TS, Grant PJ: Effects of novel polymorphisms in the RAGE gene on transcriptional regulation and their association with diabetic retinopathy. Diabetes 2001, 50:1505-1511.
35. Dewan A, Liu M, Hartman S, Zhang SS, Liu DT, Zhao C, Tam PO, Chan WM, Lam DS, Snyder M, Barnstable C, Pang CP, Hoh J: HTRA1 promoter polymorphism in wet age-related macular degeneration. Science 2006 314:989-992.

36. Yang Z, Camp NJ, Sun H, Tong Z, Gibbs D, Cameron DJ, Chen H, Zhao Y, Pearson E, Li X, Chien J, Dewan A, Harmon J, Bernstein PS, Shridhar V, Zabriskie NA, Hoh J, Howes K, Zhang K: A variant of the HTRA1 gene increases susceptibility to age-related macular degeneration. Science 2006, 314:992-993.

37. Gibbs D, Yang Z, Constantine R, Ma X, Camp NJ, Yang X, Chen H, Jorgenson A, Hau V, Dewan A, Zeng J, Harmon J, Buehler J, Brand JM, Hoh J, Cameron DJ, Dixit M, Tong Z, Zhang K: Further mapping of 10q26 supports strong association of HTRA1 polymorphisms with age-related macular degeneration. Vision Res 2008, 48:685-689.

38. Klein RJ, Zeiss C, Chew EY, Tsai JY, Sackler RS, Haynes C, Henning AK, SanGiovanni JP, Mane SM, Mayne ST, Bracken MB, Ferris FL, Ott J, Barnstable C, Hoh J: Complement factor H polymorphism in age-related macular degeneration. Science 2005, 308:385-389.

39. Chen L, Liu DT, Tam PO, Chan WM, Liu K, Chong KK, Lam DS, Pang CP: Association of complement factor $\mathrm{H}$ polymorphisms with exudative agerelated macular degeneration. Mol Vis 2006, 12:1536-1542.

40. Kondo N, Honda S, Ishibashi K, Tsukahara Y, Negi A: LOC387715/HTRA1 variants in polypoidal choroidal vasculopathy and age-related macular degeneration in a Japanese population. Am J Ophthalmol 2007, 144:608-612.

41. Tong Z, Yang Z, Patel S, et al: Promoter polymorphism of the erythropoietin gene in severe diabetic eye and kidney complications. Proc Natl Acad Sci USA 2008, 105:6998-7003.

\section{Pre-publication history}

The pre-publication history for this paper can be accessed here: http://www.biomedcentral.com/1471-2350/11/158/prepub

doi:10.1186/1471-2350-11-158

Cite this article as: Balasubbu et al:: Association analysis of nine candidate gene polymorphisms in Indian patients with type 2 diabetic retinopathy. BMC Medical Genetics 2010 11:158.

\section{Submit your next manuscript to BioMed Central and take full advantage of:}

- Convenient online submission

- Thorough peer review

- No space constraints or color figure charges

- Immediate publication on acceptance

- Inclusion in PubMed, CAS, Scopus and Google Scholar

- Research which is freely available for redistribution

Submit your manuscript at www.biomedcentral.com/submit
C Biomed Central 